\title{
Classification of posterior dynamic stabilization devices
}

\author{
Paul Khoueir, M.D., M.Sc., F.R.C.S.C., K. Anthony KIM, M.D., \\ AND Michael Y. WANG, M.D. \\ Department of Neurosurgery, University of Southern California, Los Angeles, California
}

\begin{abstract}
$\checkmark$ Numerous new posterior dynamic stabilization (PDS) devices have been developed for the treatment of disorders of the lumbar spine. In this report the authors provide a classification scheme for these devices and describe several clinical situations in which the instrumentation may be expected to play a role. By using this classification, the PDSs that are now available and those developed in the future can be uniformly categorized.
\end{abstract}

\section{KEY WORDS • facet disease • facet replacement • posterior dynamic stabilization • interspinous device classification}

I T IS ESTIMATED that up to 50 million individuals in the US suffer from symptoms related to spinal degeneration, and that in 2004 more than 1 million spinal procedures were performed to alleviate or mitigate this condition. $^{8,25}$ For the neurosurgeon treating this population, open surgical intervention has traditionally been directed at decompressive procedures to relieve neural element compression and/or fusion techniques to stabilize the spinal column.

Advancements in technology have added to the surgeon's armamentarium and necessitate new classification schemes. For example, widely adopted new surgical procedures, such as percutaneous vertebral augmentation (vertebroplasty and kyphoplasty) and total disc replacement, do not fit easily within the rubric of decompressive or fusion techniques.

One of the most rapidly evolving fields in spinal surgery is PDS. This new category of thoracolumbar spinal surgery focuses on the concept of maintaining or restoring intervertebral motion in a controlled fashion, whether by restricting the extremes of spinal movement or by dampening the kinetic energy involved in motion. The goal of these implantable devices is to mimic the behavior of the healthy spinal column (Fig. 1).

\section{Indications for PDS}

Although the indications for PDS are still being identified, there are several disorders in which the devices are expected to play a role. These are detailed in the sections that follow.

Controlled Motion in the Iatrogenically Destabilized Spine

Spinal surgery for neural entrapment syndromes typical-

Abbreviations used in this paper: FDA = Food and Drug Administration; PDS = posterior dynamic stabilization; PEEK = polyetheretherketone; TFAS = Total Facet Arthroplasty System; TOPS $=$ Total Posterior Motion Preservation System . ly involves a partial or complete laminectomy with some element of facet joint removal. Although minimal access procedures such as microdiscectomy require very little bone removal, the treatment of lumbar spinal stenosis accompanied by lateral recess stenosis and superior facet encroachment can result in significant facet joint resection. In some instances this results in iatrogenic destabilization, ${ }^{1}$ requiring the surgeon to decide whether to fuse the patient's spine primarily or watch expectantly for the finite possibility of sagittal plane imbalance or deformity. One possible role of PDS devices would be to limit and control motion after a potentially destabilizing laminectomy, avoiding the need for arthrodesis and reducing the likelihood of iatrogenic destabilization.

\section{Increased Anterior Load Sharing to Augment Interbody Fusion}

Interbody fusion techniques have become highly popular over the last two decades. Although pedicle screw/rod stabilization is typically used as an adjunct in these operations, concerns have arisen surrounding the highly rigid nature of these constructs. Stress shielding of the interbody graft is believed to be implicated in a certain percentage of pseudarthroses. ${ }^{15}$ Thus, PDS devices may play a role in limiting the extremes of motion, which could result in graft displacement, while allowing for maximal anterior load sharing and fusion.

\section{Protection and Restoration of Degenerated Facet Joints and Intervertebral Discs}

This is perhaps the most controversial and least understood indication for PDS. Contemporary surgical treatments for spinal pain generators, such as the intervertebral disc or facet joints, involve extirpation or complete destruction of the poorly functioning unit. In the case of what is believed to be discogenic pain, the disc is completely removed and replaced with an interbody fusion or arthroplasty device. Alternatively, a posterior fusion can be used to treat facet or disc disease, with the goal of pre- 


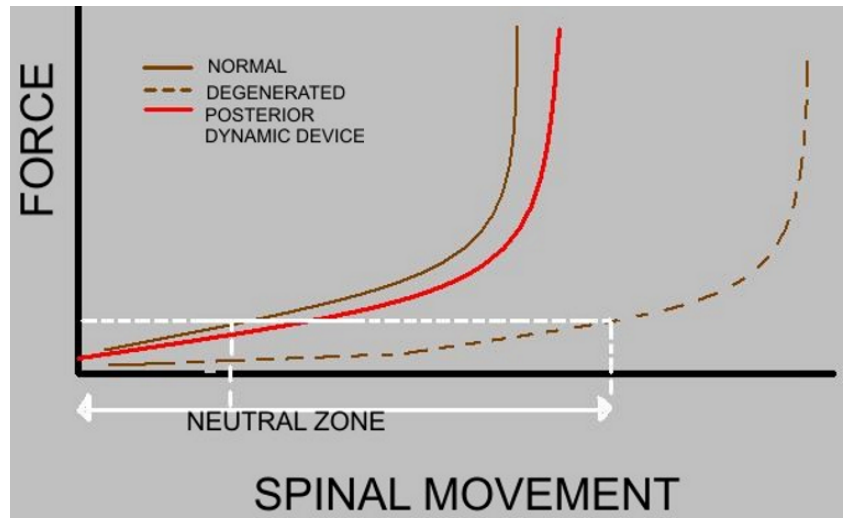

FIG. 1. Graph showing the load displacement curve of the intact spine compared with the degenerated spine, and the ideal concept of "restoring" normal motion of the degenerated spine with posterior dynamic devices.

venting any motion in the diseased unit. The PDS devices may be able to shield the disc and facet joint structures from motion that is destructive, potentially allowing for a reduction in local inflammatory processes or permitting self-repair mechanisms.

\section{In Combination With Anterior Motion Preservation for $360^{\circ}$ Circumferential Motion Segment Reconstruction}

One of the major drawbacks of total disc arthroplasty is that facet disease remains a contraindication. In fact, it is believed that disc arthroplasty may accelerate facet degeneration. ${ }^{45}$ Using PDS technology, circumferential reconstruction of all the mobile units in a spinal segment (the intervertebral disc and two facet joints) becomes possible.

\section{Adaptation of Stabilization Techniques to the Aging Spine}

Current spinal stabilization devices (pedicle screws and rods or transfacet screws) provide a high degree of rigidity. Although this can be desirable, the use of these devices in the treatment of patients with osteopenia or osteoporosis can result in catastrophic destruction of host bone at metallic interfaces. ${ }^{14}$ The application of "softer stabilization" techniques may be more desirable in these settings, reducing the likelihood of construct failure.

\section{Prevention of Fusion-Related Sequelae}

Perhaps the most widely appreciated application of PDS lies in its theoretical advantages over rigid arthrodesis. Loss of spinal motion due to fusion can result in a number of sequelae, including accelerated adjacent-level degeneration, fusion into states of malalignment, and pseudarthrosis. With respect to adjacent-level disease, it is believed that the elimination of mobility can overload adjacent segments and lead to accelerated degeneration and arthrosis. This can result in axial pain, deformity and kyphosis, and neurological compression. . $^{21,22,33,37,39}$

Furthermore, loss of lumbar lordosis as a result of poorly contoured or excessive distraction of instrumentation can lead to flatback deformity or fixed sagittal imbalance. This syndrome can result in postoperative pain, hardware failure, fatigue, and gait disturbance characterized by an inability to stand erect without flexing the knees and ex-

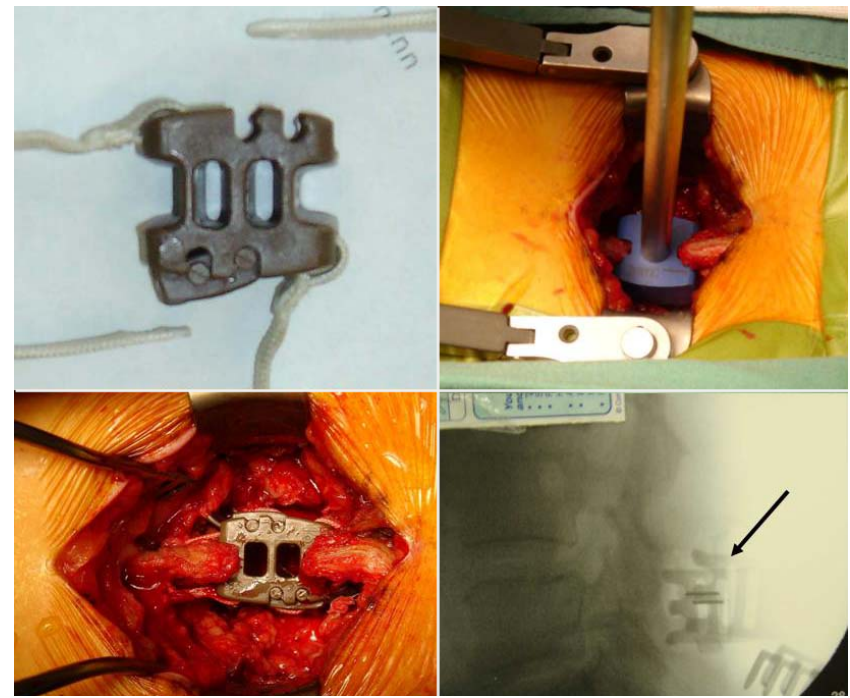

FIG. 2. Photographs and a radiographic study showing a Wallis (Abbott Spine) interspinous process stabilization device before and after implantation. This device is inserted between the spinous processes after removal of the interspinous ligament (see intraoperative view). The arrow on the radiographic study indicates the radiodense lines of the Wallis device after insertion between the spinous processes.

tending the hips to compensate for loss of segmental lumbar lordosis. ${ }^{10}$

Finally, pseudarthrosis is a significant complication of fusion surgery, with a reported incidence that can reach $30 \%$ in certain circumstances. ${ }^{5,6,46}$ Frequently, it requires repeated operation, adding to patient morbidity and costs.

\section{Classification of Devices}

Since the mid-1980s, a number of PDS devices have been introduced in the market. To simplify the discussion of these devices, we have classified them into three main categories: 1) posterior interspinous devices; 2) pediclebased dynamic rod devices; and 3) total facet replacement systems (Table 1).

TABLE 1

Classification system for PDS devices

\begin{tabular}{|c|c|c|}
\hline Classification & Indication & Device \\
\hline $\begin{array}{l}\text { interspinous } \\
\text { spacer devices }\end{array}$ & neurogenic claudication & $\begin{array}{l}\text { Wallis, X STOP, DIAM } \\
\text { Coflex, ExtendSure } \\
\text { CoRoent }\end{array}$ \\
\hline $\begin{array}{l}\text { pedicle screw/ } \\
\text { rod-based } \\
\text { devices }\end{array}$ & $\begin{array}{l}\text { to unload discs \& facets } \\
\text { to promote fusion } \\
\text { to prevent adjacent-segment } \\
\text { disease } \\
\text { to control motion in the } \\
\text { iatrogenically destabilized spine }\end{array}$ & $\begin{array}{l}\text { Graf ligament, Dynesys } \\
\text { AccuFlex rod } \\
\text { Medtronic PEEK rod } \\
\text { Scient'X Isobar }\end{array}$ \\
\hline $\begin{array}{l}\text { total facet } \\
\text { replacement } \\
\text { systems }\end{array}$ & $\begin{array}{l}\text { replacement device for } \\
\text { facet disease } \\
\text { as part of a functional } \\
\text { spine unit reconstruction } \\
\text { to prevent adjacent- } \\
\text { segment disease } \\
\text { to control motion in the } \\
\text { iatrogenically destabilized spine }\end{array}$ & $\begin{array}{l}\text { TFAS } \\
\text { TOPS } \\
\text { Stabilimax NZ }\end{array}$ \\
\hline
\end{tabular}




\section{Interspinous Spacer Devices}

The posterior interspinous devices were designed as an alternative treatment for neurogenic claudication and the pain attributed to facet joint disease. By keeping the spine in a rather flexed position, the interspinous devices increase the total canal and foraminal size, decompressing the cauda equina responsible for neurogenic claudication. ${ }^{23,34,43}$ This type of device allows neural decompression with only a minimal amount of tissue resection, making the procedure less invasive. The devices are intended to be implanted without a laminectomy and function through indirect decompression, thus avoiding the risk of epidural scarring and cerebrospinal fluid leakage. Furthermore, these devices limit extension of the spine, unload the facet joint, and relieve the pain attributed to facet disease.

The Wallis System. In 1986 the first interspinous device (Fig. 2), the Wallis System (Abbott Spine), was introduced in Europe. It was developed by Sénégas ${ }^{41}$ and has the longest history. The device's original design was a titanium block that was inserted between adjacent processes and held in place with a flat Dacron cord or ribbon wrapped around the spinous process above and below the block. After this first-generation device showed positive results, a second generation of Wallis implants was developed. The primary change was in the material used to build the interspinous block; it was changed from titanium to PEEK, a strong, plasticlike polymer that has more elasticity and is therefore less rigid than the previously used material. An important aspect of the Wallis implant is in its design and material, which minimizes the need for bone resection and avoids constraint on bone. It has notches that fit the physiological shape of the spine. ${ }^{9}$

In a prospective controlled study conducted between 1988 and 1993, more than 300 patients were treated for degenerative lesions, with positive results. This trial of the first-generation implant provided evidence that the interspinous system of nonrigid stabilization is efficacious against low-back pain caused by degenerative instability. ${ }^{3}$ These results are being confirmed with a new clinical trial of the Wallis Stabilization System, which is being regulated by the FDA. The trial is designed to compare one-or two-level surgery for lumbar degenerative disc disease with conservative treatment.

The X STOP Device. This device (St. Francis Medical Technologies, Inc.) is an oval titanium metal spacer (Fig. 3) that received FDA approval in November 2005. This implant is designed to fit between two adjacent lumbar spinous processes.

The implant procedure for this device can be done after induction of either local or general anesthesia. After a small midline incision, the paraspinal muscles are lifted subperiosteally from the spinous processes while all midline structures are left intact. The X STOP device is then placed between the spinous processes while the patient is in a slight flexion position. The supraspinous ligament is carefully protected. Starting just posterior to the lamina, a dilator is placed between the spinous processes. A sizing instrument is then inserted between the spinous processes and expanded until the supraspinous ligament is taut. Using a gauge on the sizing instrument, the X STOP device is sized (range $6-14 \mathrm{~mm}$ ) and then inserted. ${ }^{50} \mathrm{Al}-$

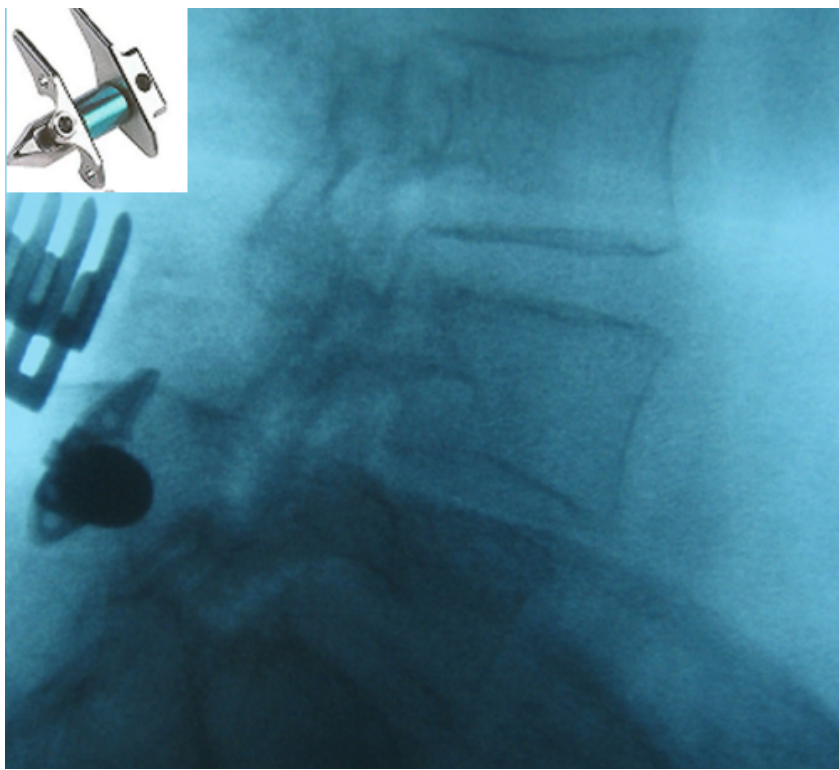

FIG. 3. Intraoperative lateral X-ray showing the X STOP device (St. Francis Medical Technologies, Inc.) after its insertion between the spinous processes. Inset: Photograph of the X STOP rigid interspinous process stabilization device.

though the implant is not rigidly attached to the osseous anatomy, it is restricted from migrating posteriorly by the supraspinous ligament, anteriorly by the lamina, cranially and caudally by the spinous processes, and laterally by the device's wings on each side. ${ }^{49}$

Several clinical studies have been performed and have shown the efficacy of the X STOP device in treating neurogenic claudication secondary to lumbar stenosis. In randomized controlled prospective multicenter trials and retrospective studies, investigators reported a better outcome with X STOP compared with conservative management. $3,49,50$

The DIAM System. The DIAM Spinal Stabilization System (Medtronic Sofamor Danek) is a soft interspinous spacer (Fig. 4). The core is made of silicone, which is covered by a polyethylene coating. The surgical technique consists of identifying the interspinous space, removing the remnants of the interspinous ligament down to the ligamentum flavum, and using a distracter of the spinous processes to facilitate the insertion of the device. It is secured in place with two laces, one around the spinous process above, and another around the one below.

Biomechanical tests have demonstrated that a posterior soft shock-absorbing implant in the lumbar spine is able to reduce intradiscal pressure, retighten posterior elements of the vertebral bodies, and reduce rotatory dislocation. ${ }^{28}$ This represents an attractive alternative for stabilizing the painful segment and yet allowing some spinal mobility. ${ }^{27}$

Few articles on the efficacy of this product have appeared in the literature..$^{9,27}$ In those studies a good satisfaction rate among patients receiving this device is reported, but the studies are all retrospective and lack controls. Today, this device is being tested in a clinical trial for FDA approval.

The Coflex, ExtendSure, and CoRoent Devices. Another 

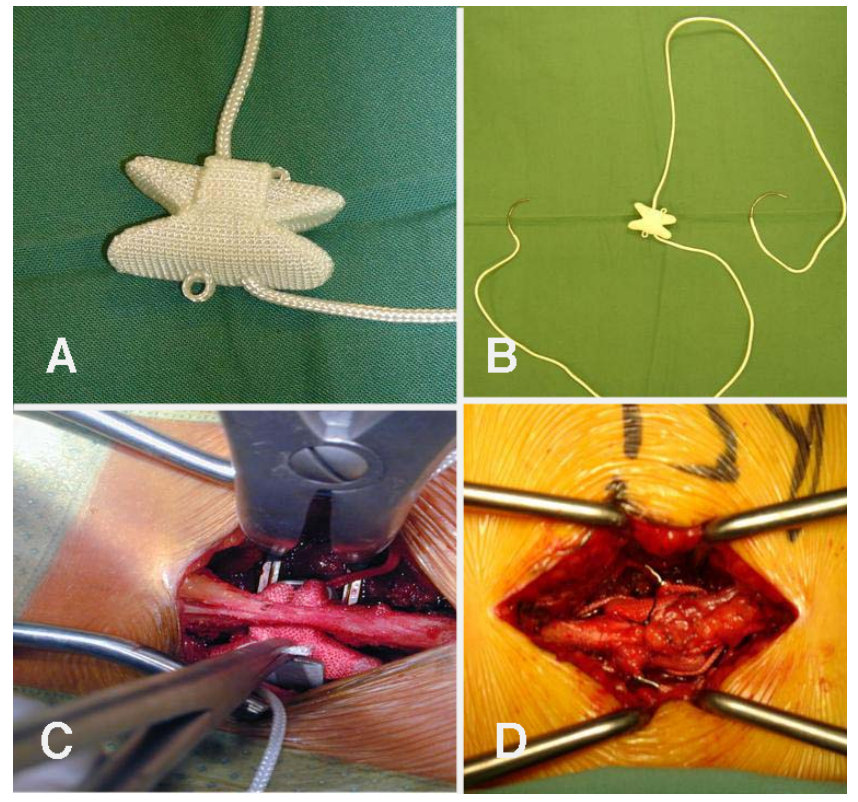

FIG. 4. Photographs showing the DIAM (Medtronic Sofamor Danek) interspinous process soft-stabilization system. This device is inserted between the spinous processes, with preservation of the interspinous ligament (see intraoperative views).

device that is used in Europe but is not currently FDA approved is the Coflex (Paradigm Spine) (Fig. 5). It is a Ushaped metallic device that is inserted between the spinous processes. As with other interspinous devices, these are designed to increase the cross-sectional diameter of the stenotic canal in patients suffering from neurogenic claudication. However, very little information is available in the literature on the biomechanics and efficacy of this product. Furthermore, ExtendSure and CoRoent (both from NuVasive) are other interspinous dynamic stabilization devices that were recently launched, in 2005 and 2006, respectively.

\section{Pedicle Screw/Rod-Based Stabilization Devices}

Pedicle-based dynamic devices were first designed to stabilize the abnormal segment and to unload degenerated discs and facet joints, while maintaining the same level of normal motion. ${ }^{42}$ By unloading the pressure on the degen-

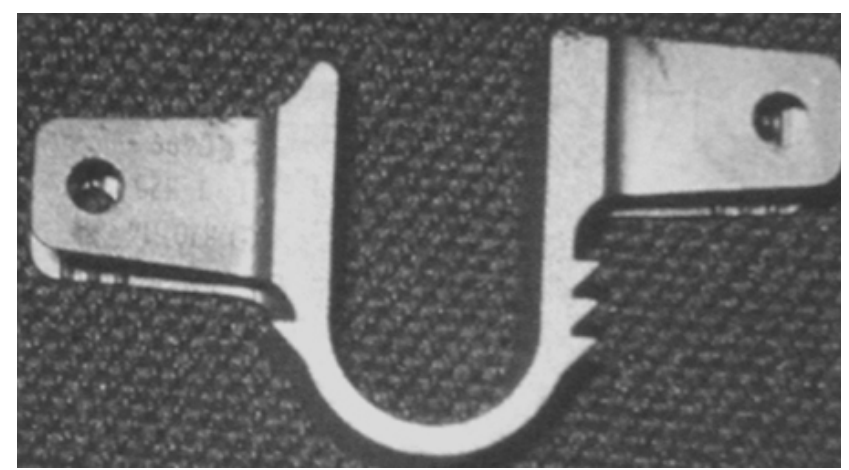

FIG. 5. Photograph showing the U-shaped Coflex device (Paradigm Spine).

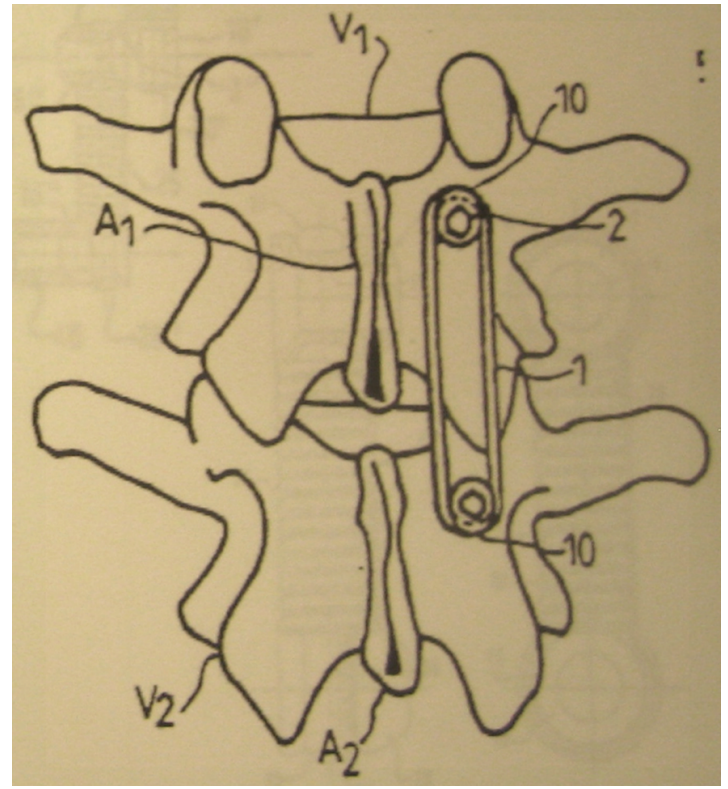

FIG. 6. Drawing from the US patent of an early ligamentoplasty model.

erated disc and facets, pedicle-based dynamic devices have the potential to reduce pain associated with these anatomical structures.

Furthermore, these devices can be used to prevent adjacent-segment disease, either by replacing the whole construct with dynamic rods or by "topping off" the rigid instrumented segment with pedicle-based dynamic devices, avoiding an abrupt change from a rigid construct to the more mobile adjacent segment. It has also been argued that using pedicle-based dynamic devices can promote better fusion because of micromovements across endplates, and can protect from implant failure because of better load sharing through the implant. Finally, these devices can be used to stabilize posterior iatrogenic destabilizing surgery, such as wide laminectomy and facetectomy.

The Graf System. The pedicle screw-based devices were first designed and launched in Europe, with Graf ligament (Surgigraft) being their first prototype (Fig. 6). The Graf system is the only pedicle-based device with polyester bands instead of rods. It is composed of 5-to 7-mm titanium pedicle screws and looped 8-mm braided polyester bands. After the spine is exposed and pedicle screws inserted, the bands are connected under applied compressive force between the pedicle screws as a ligamentoplasty. The tension and compression force used is determined by the length of the bands. ${ }^{16,18}$

The product was conceived to immobilize the lumbar spine in lordosis; alter the load bearing on the anulus and endplate; compress the posterior anulus, resulting in fewer anular tears; splint the motion segment, allowing healing of damaged tissue to occur; and relax over time, allowing some return to movement. ${ }^{17}$ However, variable outcome results are reported in the literature. Some authors showed a good outcome score in the mid-term and even long-term follow-up evaluation. ${ }^{12,16-18,24,30}$ Others were less enthusiastic with their outcome scores, and reported high revision rates. ${ }^{4,35}$ 


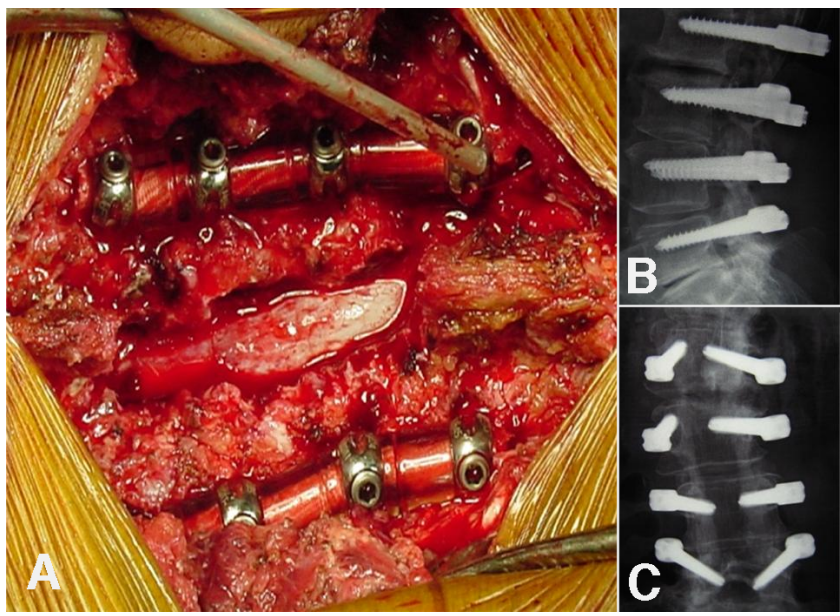

FIG. 7. A: Intraoperative photograph showing transpedicular insertion of a semirigid rod system (Dynesys; Zimmer Spine). $\mathrm{B}$ and $\mathrm{C}$ : Anteroposterior and lateral radiographic views of the instrumentation in place.

The Dynesys System. The Dynesys Spine System (Zimmer Spine), like standard frame devices, is fixed in place by using standard pedicle screws made of a titanium alloy (Fig. 7). The whole system is stabilized by polyester cords that connect the screw heads through a hollow spacer and hold the screws in place..$^{38}$

In 1991, Zimmer Spine launched the Dynesys project development, and the product was introduced in the market and first implanted in 1994. The manufacturer stated that stabilization was possible with this implant without bone grafting. In 1999, the product gained popularity in Europe. Since then 13,000 implantations have been performed worldwide, and several clinical and biomechanical studies of this product have been published.

The Dynesys devices restabilize and realign the segments in physiological position and neutralize the excessive forces. Once the devices are attached bilaterally to the affected segments, the dynamic "push-pull" relationship between the spacer and the polyester cord stabilizes the joints, keeping the vertebra in normal position. This theoretically reduces segmental motion to a physiological level, neutralizing bending, torsional, and shear forces. The stabilizing cords resist flexion movements, and the spacers resist compressive forces. The overall effect of this stabilization is designed to limit the loading of the disc. $13,32,38,40$

Several clinical studies have reported on the efficacy of the Dynesys system as a posterior stabilizing device. Prospective and retrospective studies have shown better outcome with Dynesys than with conservative treatment alone. However, those results were comparable to conventional rigid fixation, ${ }^{32,38,44}$ and a 17 to $19 \%$ rate of failure was reported in the literature. ${ }^{13,38}$ Today the Dynesys is the only FDA-approved pedicle-based dynamic device that is used not as a motion-preserving implant but as an adjunct to fusion procedures.

The AccuFlex, PEEK, and Isobar Rods. Other semirigid rods being used in the US include the AccuFlex (Globus Medical, Inc.), Medtronic's PEEK rod, and Scient'X's

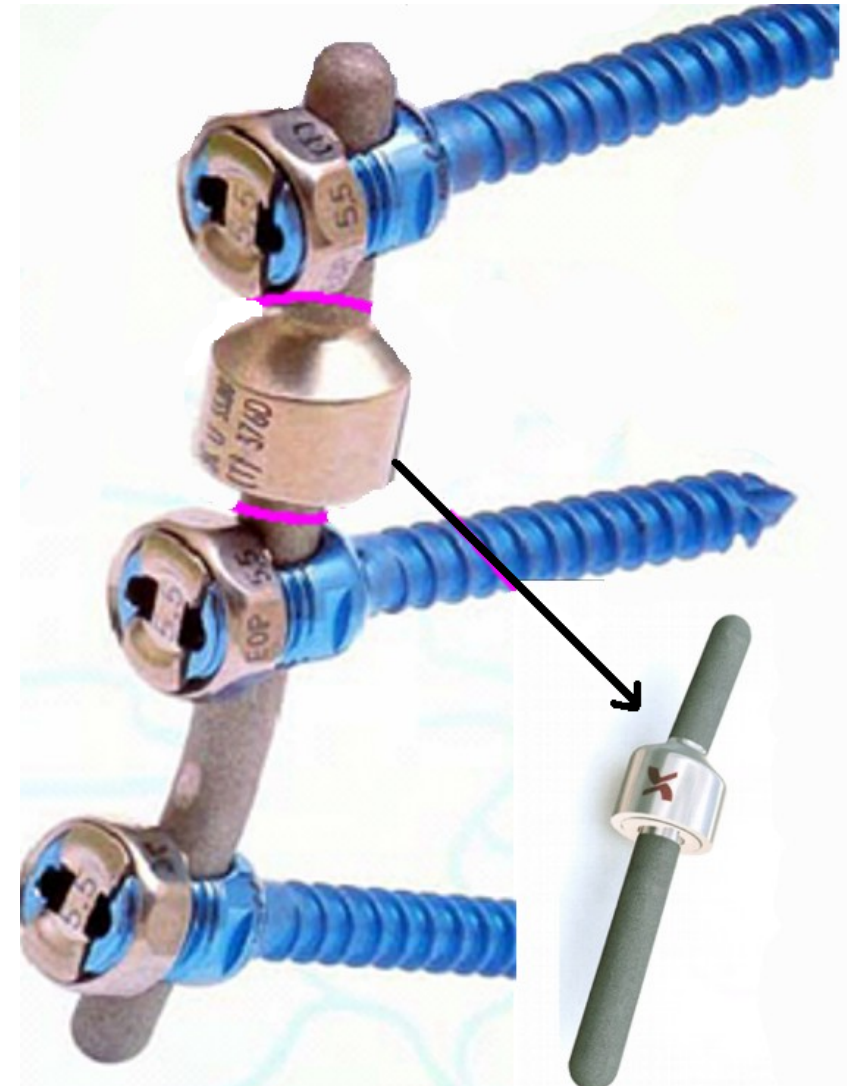

FIG. 8. Photograph showing the Isobar (Scient'X) semirigid rod system. The arrow indicates the Isobar without the screws. (Reprinted with permission.)

Isobar (Fig. 8). To date, only limited clinical and biomechanical data are available on these devices.

\section{Total Facet Replacement Systems}

Total facet replacement is an emerging new technology designed to completely restore facet joints functionally. Until recently, the focus on the intervertebral disc has resulted in an underestimation of the facet joints as a potential pain generator, and little is known about the pathogenesis of facet disease..$^{19}$ Nevertheless, the concept of facet arthropathy is not new and was first described by Goldthwait in 1911. The contemporary literature focuses on anterior column failure as leading to posterior element degeneration, with subsequent stenosis and segmental instability. 2,7,11,19,20,29,31,48 However, facetogenic pain can occur in the absence of or combined with significant disc degeneration. ${ }^{19,26,36,47,48}$ For this reason, total facet replacement and arthroplasty may be a potential treatment analogous to total disc arthroplasty for discogenic pain.

The second indication for total facet arthroplasty could be for reconstruction of the iatrogenically destabilized spine. In some instances, wide laminectomy with facetectomy is required to treat lumbar and lateral recess stenosis. Total facet arthroplasty would become an interesting adjunct to these surgeries, reducing the likelihood of iatrogenic destabilization while preserving a potentially functioning facet and averting the need for arthrodesis.

The third potential role of total facet arthroplasty would 


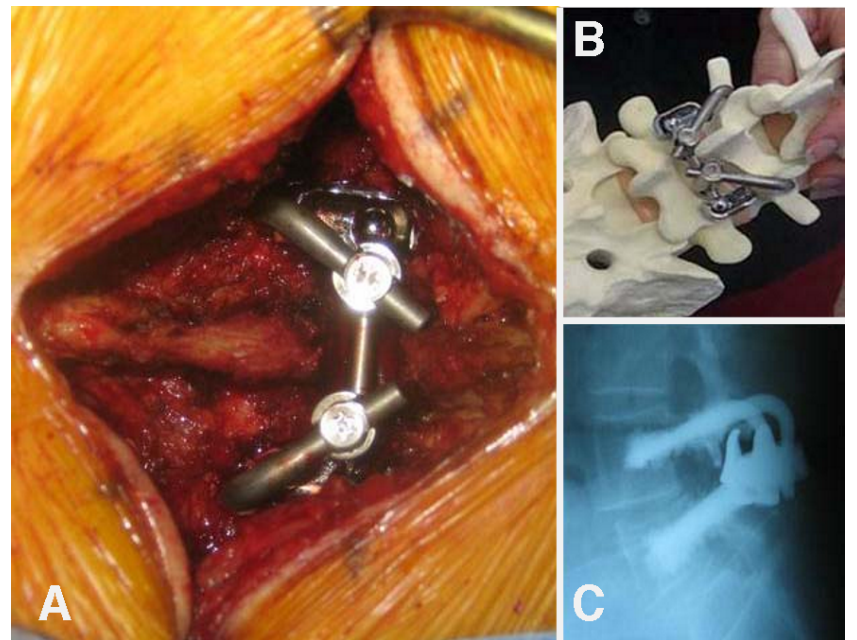

FIG. 9. A: Intraoperative photograph showing the TFAS (Archus Orthopedics) in place. B: Photograph of a model spine with the TFAS implant affixed. C: Lateral radiographic view showing the instrumentation in place.

be to augment total disc arthroplasty for complete functional spine unit reconstruction. Because facet disease remains a contraindication to disc arthroplasty, combining both technologies in a $360^{\circ}$ circumferential motion segment reconstruction would allow a broader application of these motion-preserving devices.

The TFAS Implant. The TFAS (Archus Orthopedics) is anchored with its stems fixated to the vertebral body (Fig. 9). Motion is achieved by a sphere sliding along a curved plate. An FDA-regulated multicenter prospective randomized trial for this device is currently underway to study the safety and effectiveness of TFAS compared with posterior instrumented fusion in treating moderate-to-severe lumbar stenosis that requires neural decompression and facetectomy of L3/4 and L4/5 levels.

The TOPS Implant. The TOPS (Impliant) is anchored by devices much like pedicle screws by using a standard posterior approach (Fig. 10). The posterior elements are removed and the device is implanted, occupying the same position as the posterior elements. It is a unitary device composed of a top and bottom titanium construct with an interlocking flexible polyurethane core connecting the bottom and top components. Within the polyurethane cover are "bumpers" that allow but at the same time limit the extent of motion in axial, lateral bending, and extension. Further investigations with this device are being planned, and recently it received FDA approval to begin a pivotal clinical trial.

The Stabilimax NZ Implant. Another device, the Stabilimax NZ (Applied Spine Technologies, Inc.), has recently been introduced to the market. As with the two previous devices, it is anchored in place through pedicle fixation (Fig. 11). Motion is achieved by two independent concentric springs on each side, which are incorporated into the system through connecting rods.

\section{Conclusions}

The future of PDS devices is promising. Although the

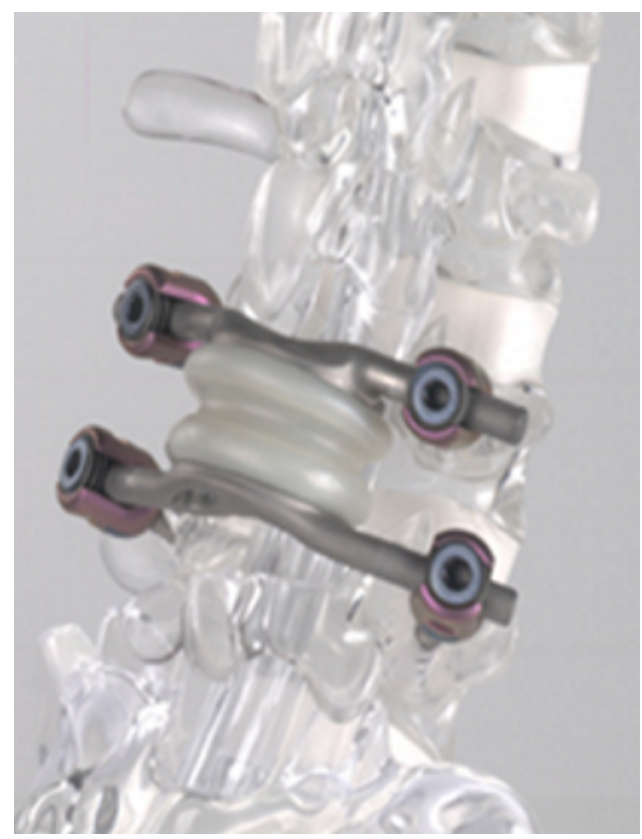

Fig. 10. Photograph showing a spine model with the TOPS instrumentation (Impliant) affixed. (Reprinted with permission.)

biomechanics, long-term clinical efficacy, and indications for these devices are not yet clear, this classification scheme will serve as a useful construct with which to view this emerging technology.

\section{Disclaimer}

The authors have no financial interest in any of the products discussed in this paper.

\section{References}

1. Abumi K, Panjabi MM, Kramer KM, Duranceau J, Oxland T, Crisco JJ: Biomechanical evaluation of lumbar spinal stability after graded facetectomies. Spine 15:1142-1147, 1990

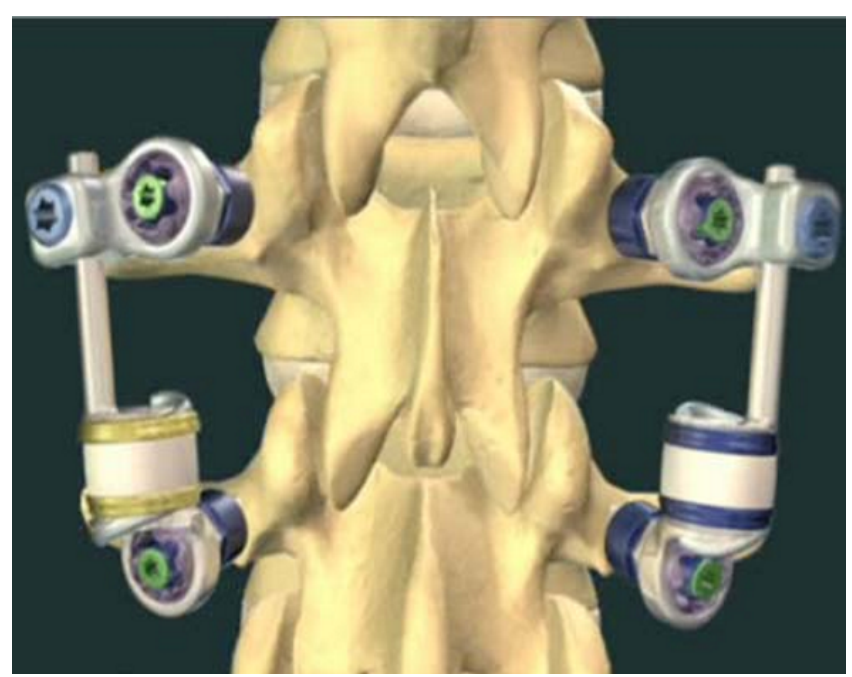

Fig. 11. Three-dimensional reconstruction of a spine showing the Stabilimax NZ device (Applied Spine Technologies, Inc.) in place. (Reprinted with permission.) 
2. Adams MA, Dolan P, Hutton WC: The stages of disc degeneration as revealed by discograms. J Bone Joint Surg Br 68: 36-41, 1986

3. Anderson PA, Tribus CB, Kitchel SH: Treatment of neurogenic claudication by interspinous decompression: application of the X STOP device in patients with lumbar degenerative spondylolisthesis. J Neurosurg Spine 4:463-471, 2006

4. Askar Z, Wardlaw D, Muthukumar T, Smith F, Kader D, Gibson S: Correlation between inter-vertebral disc morphology and the results in patients undergoing Graf ligament stabilisation. Eur Spine J 13:714-718, 2004

5. Blumenthal S, Gill K: Complications of the Wiltse Pedicle Screw Fixation System. Spine 18:1867-1871, 1993

6. Brodsky AE, Hendricks RL, Khalil MA, Darden BV, Brotzman TT: Segmental ("floating") lumbar spine fusions. Spine 14: 447-450, 1989

7. Butler D, Trafimow JH, Andersson GB, McNeill TW, Huckman MS: Discs degenerate before facets. Spine 15: 111-113, 1990

8. Cassidy JD, Cote P, Carroll LJ, Kristman V: Incidence and course of low back pain episodes in the general population. Spine 30:2817-2823, 2005

9. Christie SD, Song JK, Fessler RG: Dynamic interspinous process technology. Spine 30 (16 Suppl): S73-S78, 2005

10. Farcy JP, Schwab FJ: Management of flatback and related kyphotic decompensation syndromes. Spine 22:2452-2457, 1997

11. Fujiwara A, Lim TH, An HS, Tanaka N, Jeon CH, Andersson $\mathrm{GB}$, et al: The effect of disc degeneration and facet joint osteoarthritis on the segmental flexibility of the lumbar spine. Spine 25:3036-3044, 2000

12. Gardner A, Pande KC: Graf ligamentoplasty: a 7-year followup. Eur Spine J 11 (2 Suppl): S157-S163, 2002

13. Grob D, Benini A, Junge A, Mannion AF: Clinical experience with the Dynesys semirigid fixation system for the lumbar spine: surgical and patient-oriented outcome in 50 cases after an average of 2 years. Spine 30:324-331, 2005

14. Hasegawa K, Homma T, Uchiyama S, Takahashi H: Vertebral pseudarthrosis in the osteoporotic spine. Spine 23:2201-2206, 1998

15. Heggeness MH, Esses SI: Classification of pseudarthroses of the lumbar spine. Spine 16 (8 Suppl): S449-S454, 1991

16. Kanayama M, Hashimoto T, Shigenobu K: Rationale, biomechanics, and surgical indications for Graf ligamentoplasty. Orthop Clin North Am 36:373-377, 2005

17. Kanayama M, Hashimoto T, Shigenobu K, Harada M, Oha F, Ohkoshi Y, et al: Adjacent-segment morbidity after Graf ligamentoplasty compared with posterolateral lumbar fusion. J Neurosurg 95:5-10, 2001

18. Kanayama M, Hashimoto T, Shigenobu K, Oha F, Ishida T, Yamane S: Non-fusion surgery for degenerative spondylolisthesis using artificial ligament stabilization: surgical indication and clinical results. Spine 30:588-592, 2005

19. Kim KY, Wang MY: Magnetic resonance image-based morphological predictors of single photon emission computed tomography-positive facet arthropathy in patients with axial back pain. Neurosurgery 59:147-157, 2006

20. Koeller W, Muehlhaus S, Meier W, Hartmann F: Biomechanical properties of human intervertebral discs subjected to axial dynamic compression-influence of age and degeneration. J Biomech 19:807-816, 1986

21. Kwon BK, Elgafy H, Keynan O, Fisher CG, Boyd MC, Paquette SJ, et al: Progressive junctional kyphosis at the caudal end of lumbar instrumented fusion: etiology, predictors, and treatment. Spine 31:1943-1951, 2006

22. Lehmann TR, Spratt KF, Tozzi JE, Weinstein JN, Reinarz SJ, el-Khoury GY, et al: Long-term follow-up of lower lumbar fusion patients. Spine 12:97-104, 1987

23. Lindsey DP, Swanson KE, Fuchs P, Hsu KY, Zucherman JF,
Yerby SA: The effects of an interspinous implant on the kinematics of the instrumented and adjacent levels in the lumbar spine. Spine 28:2192-2197, 2003

24. Madan S, Boeree NR: Outcome of the Graf ligamentoplasty procedure compared with anterior lumbar interbody fusion with the Hartshill horseshoe cage. Eur Spine J 12:361-368, 2003

25. Manchikanti L: Epidemiology of low back pain. Pain Physician 3:167-192, 2000

26. Manchikanti L, Boswell MV, Singh V, Pampati V, Damron KS, Beyer CD: Prevalence of facet joint pain in chronic spinal pain of cervical, thoracic, and lumbar regions. BMC Musculoskelet Disord 5:15, 2004

27. Mariottini A, Pieri S, Giachi S, Carangelo B, Zalaffi A, Muzii FV, et al: Preliminary results of a soft novel lumbar intervertebral prothesis (DIAM) in the degenerative spinal pathology. Acta Neurochir Suppl 92:129-131, 2005

28. Minns RJ, Walsh WK: Preliminary design and experimental studies of a novel soft implant for correcting sagittal plane instability in the lumbar spine. Spine 22:1819-1827, 1997

29. Moore RJ, Crotti TN, Osti OL, Fraser RD, Vernon-Roberts B: Osteoarthrosis of the facet joints resulting from anular rim lesions in sheep lumbar discs. Spine 24:519-525, 1999

30. Onda A, Otani K, Konno S, Kikuchi S: Mid-term and long-term follow-up data after placement of the Graf stabilization system for lumbar degenerative disorders. J Neurosurg Spine 5: 26-32, 2006

31. Peterson CK, Bolton JE, Wood AR: A cross-sectional study correlating lumbar spine degeneration with disability and pain. Spine 25:218-223, 2000

32. Putzier M, Schneider SV, Funk J, Perka C: [Application of a dynamic pedicle screw system (DYNESYS) for lumbar segmental degenerations-comparison of clinical and radiological results for different indications.] Z Orthop Ihre Grenzgeb 142:166-173, 2004 (Ger)

33. Rahm MD, Hall BB: Adjacent-segment degeneration after lumbar fusion with instrumentation: a retrospective study. J Spinal Disord 9:392-400, 1996

34. Richards JC, Majumdar S, Lindsey DP, Beaupre GS, Yerby SA: The treatment mechanism of an interspinous process implant for lumbar neurogenic intermittent claudication. Spine 30: 744-749, 2005

35. Rigby MC, Selmon GP, Foy MA, Fogg AJ: Graf ligament stabilisation: mid-to long-term follow-up. Eur Spine J 10: 234-236, 2001

36. Schendel MJ, Dekutoski MB, Ogilvie JW, Olsewski JM, Wallace LJ: Kinematics of the canine lumbar intervertebral joint. An in vivo study before and after adjacent instrumentation. Spine 20:2555-2564, 1995

37. Schlegel JD, Smith JA, Schleusener RL: Lumbar motion segment pathology adjacent to thoracolumbar, lumbar, and lumbosacral fusions. Spine 21:970-981, 1996

38. Schnake KJ, Schaeren S, Jeanneret B: Dynamic stabilization in addition to decompression for lumbar spinal stenosis with degenerative spondylolisthesis. Spine 31:442-449, 2006

39. Schulitz KP, Wiesner L, Wittenberg RH, Hille E: [The mobile segment above fusion.] Z Orthop Ihre Grenzgeb 134: 171-176, 1996 (Ger)

40. Schwarzenbach O, Berlemann U, Stoll TM, Dubois G: Posterior dynamic stabilization systems: DYNESYS. Orthop Clin North Am 36:363-372, 2005

41. Senegas J: Mechanical supplementation by non-rigid fixation in degenerative intervertebral lumbar segments: the Wallis system. Eur Spine J 11 Suppl 2: S164-169, 2002

42. Sengupta DK, Mulholland RC: Fulcrum assisted soft stabilization system: a new concept in the surgical treatment of degenerative low back pain. Spine 30:1019-1030, 2005

43. Siddiqui M, Karadimas E, Nicol M, Smith FW, Wardlaw D: Effects of X-STOP device on sagittal lumbar spine kinematics in spinal stenosis. J Spinal Disord Tech 19:328-333, 2006 
44. Stoll TM, Dubois G, Schwarzenbach O: The dynamic neutralization system for the spine: a multi-center study of a novel non-fusion system. Eur Spine J 11 (2 Suppl): S170-S178, 2002

45. van Ooij A, Oner FC, Verbout AJ: Complications of artificial disc replacement: a report of 27 patients with the SB Charite disc. J Spinal Disord Tech 16:369-383, 2003

46. West JL III, Bradford DS, Ogilvie JW: Results of spinal arthrodesis with pedicle screw-plate fixation. J Bone Joint Surg Am 73:1179-1184, 1991

47. Yang KH, King AI: Mechanism of facet load transmission as a hypothesis for low-back pain. Spine 9:557-565, 1984

48. Zander T, Rohlmann A, Klockner C, Bergmann G: Influence of graded facetectomy and laminectomy on spinal biomechanics. Eur Spine J 12:427-434, 2003

49. Zucherman JF, Hsu KY, Hartjen CA, Mehalic TF, Implicito
DA, Martin MJ, et al: A multicenter, prospective, randomized trial evaluating the X STOP interspinous process decompression system for the treatment of neurogenic intermittent claudication: two-year follow-up results. Spine 30:1351-1358, 2005

50. Zucherman JF, Hsu KY, Hartjen CA, Mehalic TF, Implicito DA, Martin MJ, et al: A prospective randomized multi-center study for the treatment of lumbar spinal stenosis with the $\mathrm{X}$ STOP interspinous implant: 1-year results. Eur Spine J 13: 22-31, 2004

Manuscript received October 26, 2006.

Accepted November 22, 2006.

Address reprint requests to: Michael Y. Wang, M.D., Department of Neurosurgery, University of Southern California, 1200 North State Street, Suite 5046, Los Angeles, California 90033. email: myw@usc.edu. 